\title{
Bleeding diathesis due to thromboxane synthesis deficiency
}

INSERM

\section{Source}

INSERM. (1999). Orphanet: an online rare disease and orphan drug data base. Bleeding diathesis due to thromboxane synthesis deficiency. ORPHA:220443

Bleeding diathesis due to thromboxane synthesis deficiency is a rare, genetic, isolated constitutional thrombocytopenia disease characterized by impaired platelet aggregation resulting from a defect in thromboxane synthesis or signaling, manifesting with mild to moderate mucocutaneous, gastrointestinal or surgical bleeding (e.g. easy bruising, prolonged epistaxis, excessive bleeding after a tooth extraction). 